\title{
PRESSURE CONTROL CHARACTERISTICS OF ELECTRO-PNEUMATIC REGULATOR WITH TWO MULTILAYERED PZT VALVES
}

\author{
So-Nam Yun*, Young-Bog Ham*, Jung-Ho Park*, Deok-Yong Ham* and Il-Young Lee** \\ * Korea Institute of Machinery and Materials(KIMM) \\ 104 Shinsung-Rho, Yuseong-Gu, Daejeon, 305-343 KOREA \\ (E-mail: ysn688@kimm.re.kr) \\ ** Department of Mechanical Engineering, College of Engineering, Pukyung National University \\ 599-1, Daeyeon 3-dong, Nam-gu, Busan, 608-737 Korea
}

\begin{abstract}
This paper presents pressure control method using the electro-pneumatic regulator with two multilayered PZT valves. An electro-pneumatic regulator is a type of pressure control valve that is a combination of a poppet valve for main pressure control, two multilayered PZT valves for pilot pressure control, a microprocessor with a feedback controller and a pressure sensor. The benefits of bender type PZT actuator are faster response times, low energy consumption, and the ability to be used in hazardous environments and field bus systems. Solenoid actuator for electro-pneumatic regulator is widely used but this actuator has a high power consumption characteristics. So PZT actuator is required for the energy saving.

In this study, a multilayered bender type PZT actuator of $27.0 \mathrm{~mm}(\mathrm{~L}) \times 9.0 \mathrm{~mm}(\mathrm{~W}) \times 0.8(\mathrm{~mm})$ with a constant of $220 \mathrm{e}-12$ $\mathrm{m} / \mathrm{V}$ and 20 sheets of PZT thin film was fabricated and experimented. The experiments for On-Off control and PID-PWM control of the electro-pneumatic regulator were operated under the input condition of $0.5 \mathrm{MPa}$. From the experiments, the performance characteristics of the fabricated electro-pneumatic regulator were evaluated. A new control method for precise proportional pressure control using the electro-pneumatic regulator with two PZT valves was suggested. Using this suggested model, all possible operating conditions were analyzed.
\end{abstract}

\section{KEY WORDS}

electro-pneumatic regulator, pressure control, PZT actuator, microvalve, PID-PWM control

\section{INTRODUCTION}

The benefits of the pneumatic valve with bimorph type piezoelectric actuator are faster response times, low energy consumption, and the ability to be used in hazardous environments and field bus systems [1]. However, the PZT actuator has hysteresis nonlinearity due to the ferroelectric characteristics of the PZT elements $[2,3]$. This causes problems in the pressure control characteristics and deteriorates the performance of the system [4, 5]. In order to overcome the abovementioned problem, the methods of a PZT actuator performance improvement and a electro-pneumatic regulator(E-P regulator) using two PZT microvalves have been studied[6, 7].

In this study, a multilayered bender type PZT actuator of $27.0 \mathrm{~mm}(\mathrm{~L}) \times 9.0 \mathrm{~mm}(\mathrm{~W}) \times 0.8 \mathrm{~mm}(\mathrm{t})$ with a constant of $220 \mathrm{e}-12 \mathrm{~m} / \mathrm{V}$ and 20 sheets of PZT thin film was fabricated and experimented. The maximum operating force of $0.35 \mathrm{~N}$ and maximum displacement of $80 \mu \mathrm{m}$ by input condition of $40 \mathrm{~V}$ were achieved from the fabricated PZT actuator. The rising and the falling time constant of this actuator under the input pressure of 
$0.5 \mathrm{MPa}$ were $0.29 \mathrm{~s}$ and $0.19 \mathrm{~s}$ respectively. The experiments for On-off control and PID-PWM control of the E-P regulator were operated under the input condition of $0.5 \mathrm{MPa}$. From the experiments, the performance characteristics of the fabricated E-P regulator were evaluated. The pressure hysteresis of $\pm 2.5 \%$ and the time constant of $150 \mathrm{~ms}$ under the flow input condition of $2001 \mathrm{pm}$ were measured through the manufactured experimental setup and it was confirmed that the proposed mechanism has good control characteristics to the response sensitivity and hysteresis.

\section{STRUCTURE AND OPERATING PRINCIPAL OF THE ELECTRO-PNEUMATIC REGULATOR}

Fig.1 shows the control flow diagram of the developed E-P regulator. The developed product is a pressure control valve that is a combination of a main poppet valve, two PZT microvalves, a microprocessor and a pressure sensor with a built-in feedback function. The open area of the poppet type output valve is controlled by two PZT microvalves. There is a built-in diaphragm device in the poppet type output valve to receive the pilot pressure. The two PZT microvalves have a multilayered bender type PZT actuator. It is operated in an alternating way by means of PWM signals generated by the controller. A microprocessor is embedded in the controller, which calculates input signals and signals from the pressure sensor in real time. The difference values are then sent to the two PZT microvalves respectively and main output pressure is controlled. The display device turns a voltage into a pressure for a user to easily check the controlled pressure of the system. The pressure sensor is installed on the output unit of the output valve and plays the eventual role of transmitting the pressure information to the controller.

\section{DESIGN AND MANUFACTURING}

Fig. 2 shows the appearance and inner structure of a PZT actuator designed to use for a pilot valve. Fig. 3 shows the displacement results, which were calculated using Atila Software. Fig. 4 shows the manufactured PZT actuator. In this study, the manufactured PZT actuator has a 20-layered structure, dimensions of $27.0 \mathrm{~mm}(\mathrm{~L}) \times 9.0 \mathrm{~mm}(\mathrm{~W}) \times 0.8 \mathrm{~mm}(\mathrm{t})$ with a constant of

\section{DESIGN AND MANUFACTURING}

$220 \mathrm{e}-12 \mathrm{~m} / \mathrm{V}$. Fig. 5 indicates the inner structure and assembled appearance of the microvalve using the designed and manufactured PZT actuator. As mentioned previously, two microvalves are used as pilot valves for supply and delivery, respectively. Fig. 6 shows the structure view of the manufactured main body.

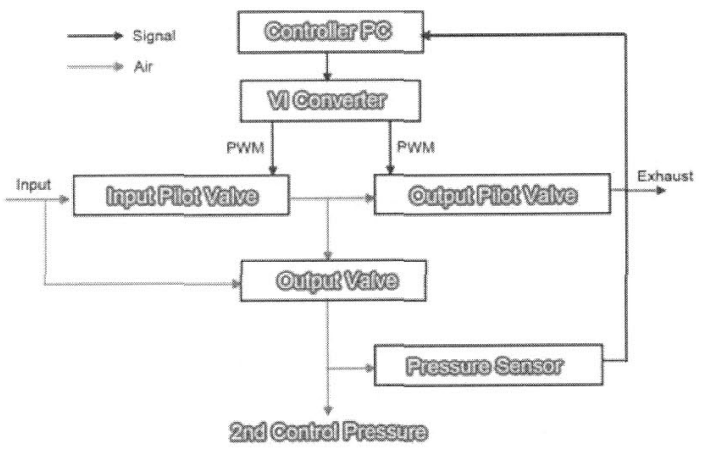

Figure 1 Control flow E-P regulator
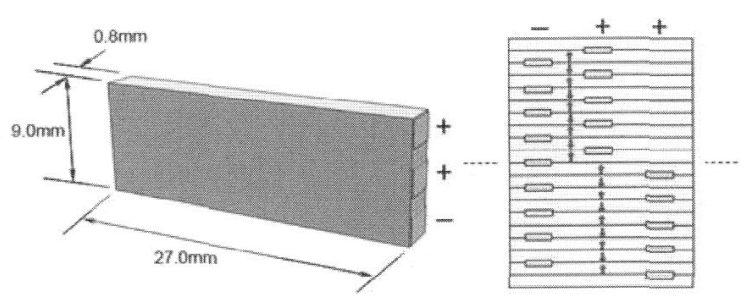

Figure 2 Multilayered bender type PZT actuator

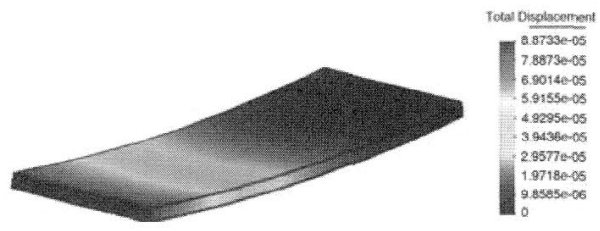

Figure 3 Displacement analysis result

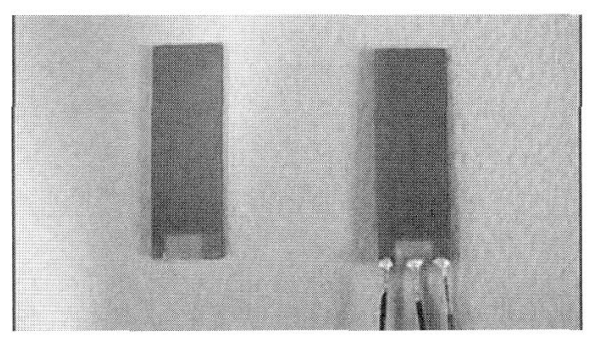

Figure 4 Photo view of manufactured PZT actuator

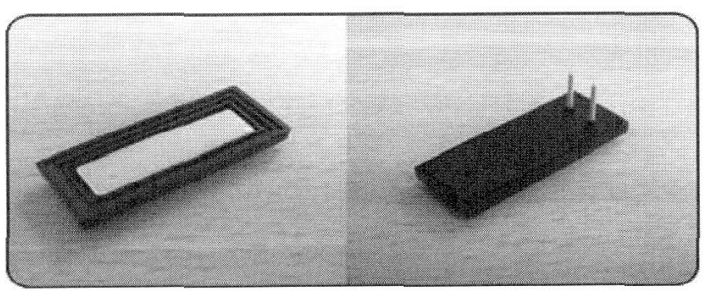

Figure 5 Photo view of PZT microvalve 


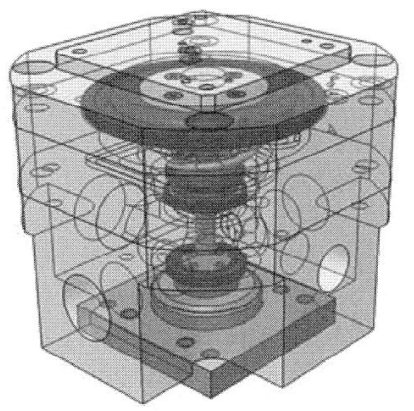

Figure 6 Structure view of main body

\section{PERFORMANCE TEST RESULTS}

Fig. 7 indicates the test results of the displacement characteristics of the designed and manufactured multilayered bender type PZT actuator. From the results we can get that more than $150 \mu \mathrm{m}$ of displacement was observed at $80 \mathrm{~V}$. In addition, in terms of force characteristics it is verified to be used at a working pressure without any problems. Fig. 8 shows the manufactured experimental setup in order to evaluate the performance of the developed regulator. The developed regulator was compared with the conventional solenoid type, and a control technique to improve the performance of the regulator itself was studied. Tests were performed in three different conditions; one with On/Off control only, another with PID-PWM control, and the other with PID-PWM-Saturation function control. The test conditions were as follows: pressure of $0.4[\mathrm{MPa}]$, sampling time of $0.001[\mathrm{~s}]$, PWM signal frequency of $20[\mathrm{~Hz}]$, step signal period of $1[\mathrm{~s}](\mathrm{On}) \sim 8[\mathrm{~s}](\mathrm{OFF})$, control reference signal of $0[\mathrm{~V}] \sim 4[\mathrm{~V}] \sim 0[\mathrm{~V}]$, PID gain of $k_{p}=1.1, k_{i}=0.001$ and $k_{d}=0.001$. For the data acquisition equipment and software, NI-6062E of NI and Simulink14 of Matlab were used respectively to measure experimental data.

Fig. 9 indicates the Simulink block diagrams for the experiment with PID-PWM control, and PID-PWM-Saturation function control. Here, In the case of (a), the final control signal is turned from a PID control signal into a PWM signal. In the case of (b), the control method is identical to the case of (a), and the system is run smoothly by providing an arbitrary control limit.

Fig. 10 shows the experimental results of applying a PID-PWM control technique to the solenoid method and the PZT one, respectively. PID gain was not optimized, and an identical gain is applied to both regulators. The results of the PZT method were the same as in the solenoid method.

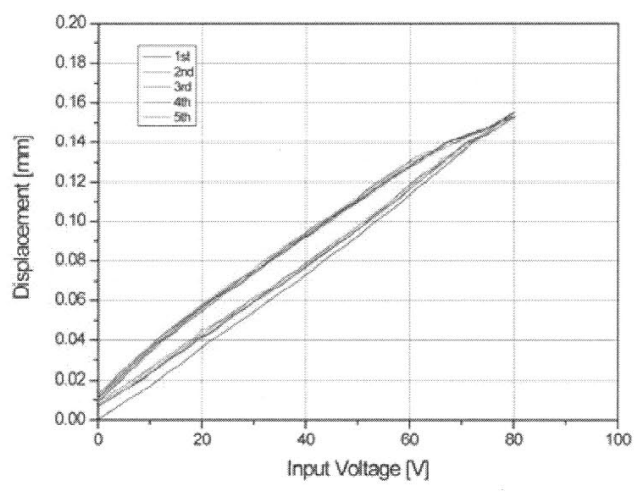

Figure 7 Displacement results of PZT actuator

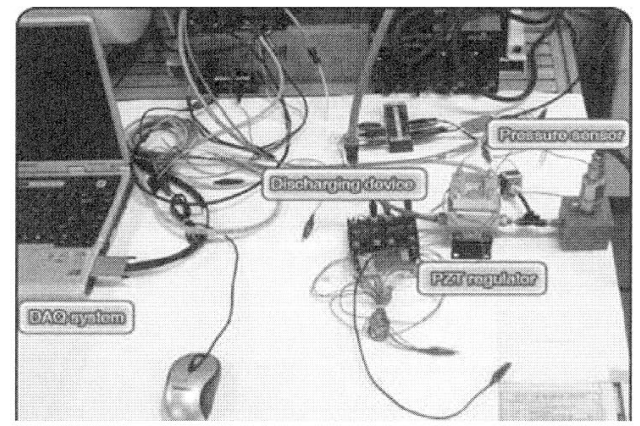

Figure 8 Experimental setup for E-P regulator

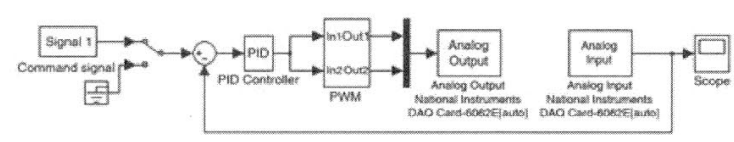

a) PID-PWM control block

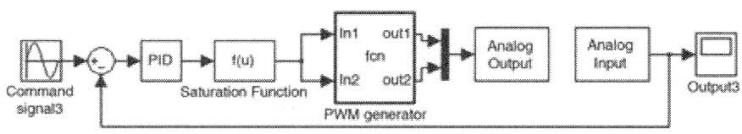

b) PID-PWM-saturation function control block

Figure 9 Pressure control block using Simulink

Fig. 11 indicates the results of the application of the saturating function to the conventional PWM control method in order to improve the hysteresis characteristics of a PZT type regulator. When $k=1$, linearity improve, but hysteresis deteriorates, while when $k=2$, both linearity and hysteresis improve. The developed controller makes it possible to adjust this value, depending on the performance of the system. 


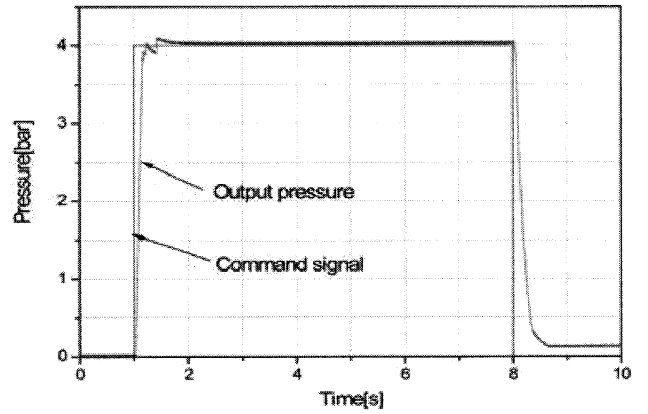

a) solenoid microvalve

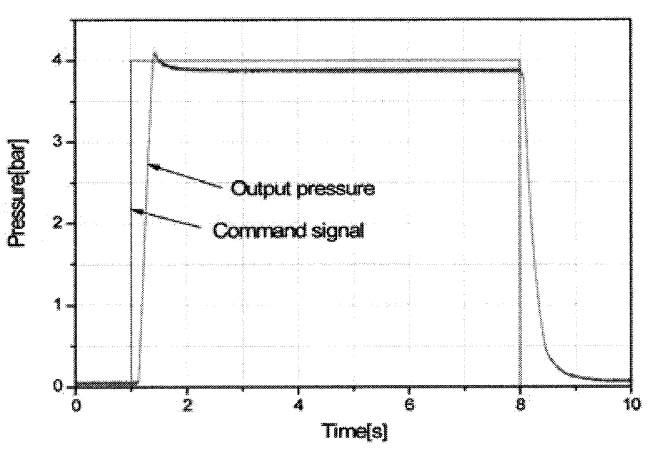

b) PZT microvalve

Figure 10 Pressure control results using PID-PWM method

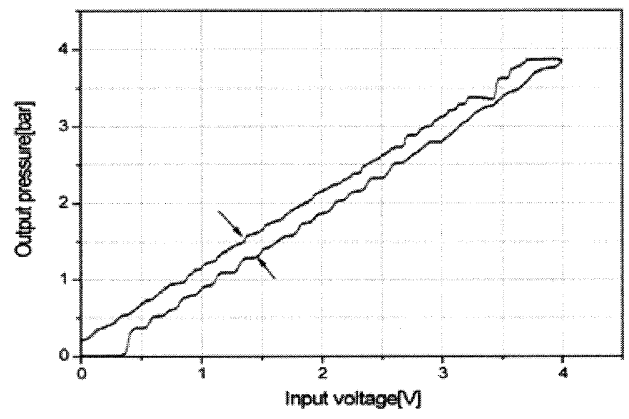

a) Saturation function $\mathrm{k}=1$

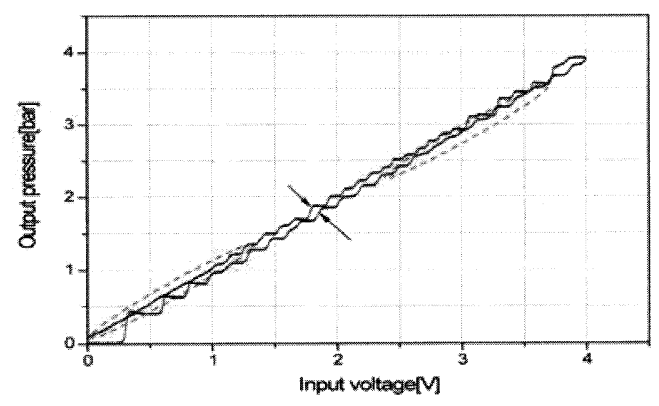

b) Saturation function $\mathrm{k}=2$

Figure 11 Pressure hysteresis results using PID-PWM-Saturation function method

\section{CONCLUSION}

The developed regulator can be used in a wide range of fields, such as semiconductor manufacture, automobile, automation production line, package line, field bus and solar heat energy system. In terms of energy efficiency, it has numerous good characteristics, and for this reason we can anticipate that there will be very high demand for this product, and it will be eventually contribute to energy savings.

However, there are a couple of problems to be solved before it is able to replace the conventional solenoid actuator.

First, the stability of the PZT actuator needs to be ensured. To run at a low voltage and have large displacement and high drivability, a few $\mu \mathrm{m}$ thin film PZT and scores of multilayered process are needed. To achieve this, laminate, polarization and cutting techniques are of great importance, and they should be first solved in order to obtain stability of the PZT actuator.

Second, the PZT actuator is driven at a higher voltage than conventional solenoid actuators. The PZT actuator has condenser characteristics, and in order improve response characteristics, a discharge technique is needed.

Third, durability and reliability also need to be secured. The weakest point of a PZT actuator, which is its brittleness, must be improved, and performance must be raised to a high level of reliability, to the point that there are no problems even after tens of thousands of repetitive operations are performed.

\section{REFERENCES}

1. Lou Nohos, NCFP 102-6.7, 2002, pp.179-181.

2. M. Weinmann, M. Muth, M. Giousouf, C. Hanisch and P. Post, State of the art in pneumatic microvalves, Actuator 2002-B 1.0, 2002, pp.217-222.

3. M. Weinmann, A. J. Schmid, M. Fuss, Piezoelectric pneumatic valves, Actuator 2006-A 5.2 ,2006, pp.181-184.

4. P. Mandurino, P.M. Weaver, Electronic domestic gas valve proportionally controlled using piezo actuators, Actuator 2004-A 4.7, 2004, pp.152-155.

5. Hubertus Murrenhoff, Innovative designs and control circuits for proportional valves, NCFP 102-27.2/SAE OH 2002-01-1458, 2002, pp.691-701.

6. So-Nam Yun, Kyung-Woo Lee, Hong-Hee Kim and Hyung-Jong So, Development of the pneumatic valve with bimorph type piezoelectric actuator, Materials chemistry and physics, 2006, pp.1-4.

7. So-Nam Yun, Young-Bog Ham, Jung-Ho Park, Woo-Seok Seo and Kyung-Woo Lee, Electropneumatic regulator strategy using two PZT actuator, ATEM'07, 2007, pp. 208. 